\title{
Maternal imprinting effect on $B$ chromosome transmission in rye
}

M. J. Puertas, M. M. Jiménez, F. Romera, J. M. Vega and M. Díez
Departamento de Genética, Facultad de Biología, Universidad Complutense, 28040 Madrid, Spain.

$A$ new feature affecting the transmission rate of rye $B$ chromosomes is described. Progenies of $0 \mathrm{~B} \times 2 \mathrm{~B}, 2 \mathrm{~B} \times 0 \mathrm{~B}$ and $2 B \times 2 B$ crosses were studied, considering both the $B$ chromosome number of the plants crossed and that of their maternal parents. A remarkably large variation within these progenies was observed. The variation found in $0 \mathrm{~B} \times 2 \mathrm{~B}$ crosses was mainly due to the effect of the maternal parent of the males and females involved: pollen grains formed in 2B plants whose maternal parent had $2 B$ s transmitted B chromosomes at high frequency; $0 B$ plants whose maternal parent had 2B, accepted pollen with Bs at high frequency. Conversely, 2B males and $0 B$ females with $0 B$ maternal parent, formed progeny with $B$ chromosomes at a much lower frequency.

A very large variation in $B$ chromosome frequency was also observed in progenies of $2 B \times 0 B$ crosses although in this case the maternal parent of $2 B$ females does not seem to be the cause of such variation.

The observed progenies of $2 \mathrm{~B} \times 2 \mathrm{~B}$ crosses fitted with expectations only when the effect of the maternal parent of the plants used for crosses was considered. The interaction between females having a $2 B$ maternal parent with $2 B$ pollen, and the effect of the male maternal parent was also evident in this case.

It seems that 2B chromosomes produce an imprinting in plants, in such a way that all their descendants can be recognised whether they carry Bs or not. The frequency of transmission of $B$ chromosomes is increased through the plants with a 2B maternal parent. A OB maternal parent causes the transmission frequency to decrease. We believe that these interactions have an important effect at the population level on the maintenance of the polymorphism for B chromosomes.

\section{INTRODUCTION}

In almost all species studied the transmission of $\mathrm{B}$ chromosomes is nonMendelian. In rye, the most obvious and best known causes of this behaviour are their peculiar meiosis (Kishikawa, 1965) and the directed nondisjunction of the B chromosome which occurs during gametogenesis (Müntzing, 1946; Håkanson, 1948). However, these features are not the only phenomena which causes the transmission of $\mathrm{B}$ chromosomes to deviate from Mendelian expectations.

Table 1 (modified from Matthews, 1981) shows a summary of all crosses, reported to date, involving $\mathrm{OB}$ and $2 \mathrm{~B}$ rye plants. Two types of variation of the number of Bs among the progenies are remarkable: (i) the variation among $B$ classes within crosses and (ii) the variation of the frequency of $B$ classes among crosses. The source of the first type of variation is the nonMendelian behaviour of $\mathrm{B}$ chromosomes during gametogenesis. The cause of the second type of variation is unknown.

In the present work we have studied progenies obtained in $0 \mathrm{~B} \times 2 \mathrm{~B}, 2 \mathrm{~B} \times 0 \mathrm{~B}$ and $2 \mathrm{~B} \times 2 \mathrm{~B}$ crosses considering both the $\mathrm{B}$ number of the plants used in the crosses, as males or females, and that of their maternal parents. The objective was to investigate whether the transmission of gametes with different numbers of Bs is influenced by the $B$ number of the maternal parent of the plants used in the crosses.

\section{MATERIAL AND METHODS}

The material used was Secale cereale with B chromosomes from the Puyo population (Korea), which was kindly provided by Dr Lee (Seoul National University).

Chromosome counts were made during two consecutive years in order to obtain plants with 0 
Table 1 Progeny obtained in crosses involving $0 \mathrm{~B}$ and $2 \mathrm{~B}$ plants

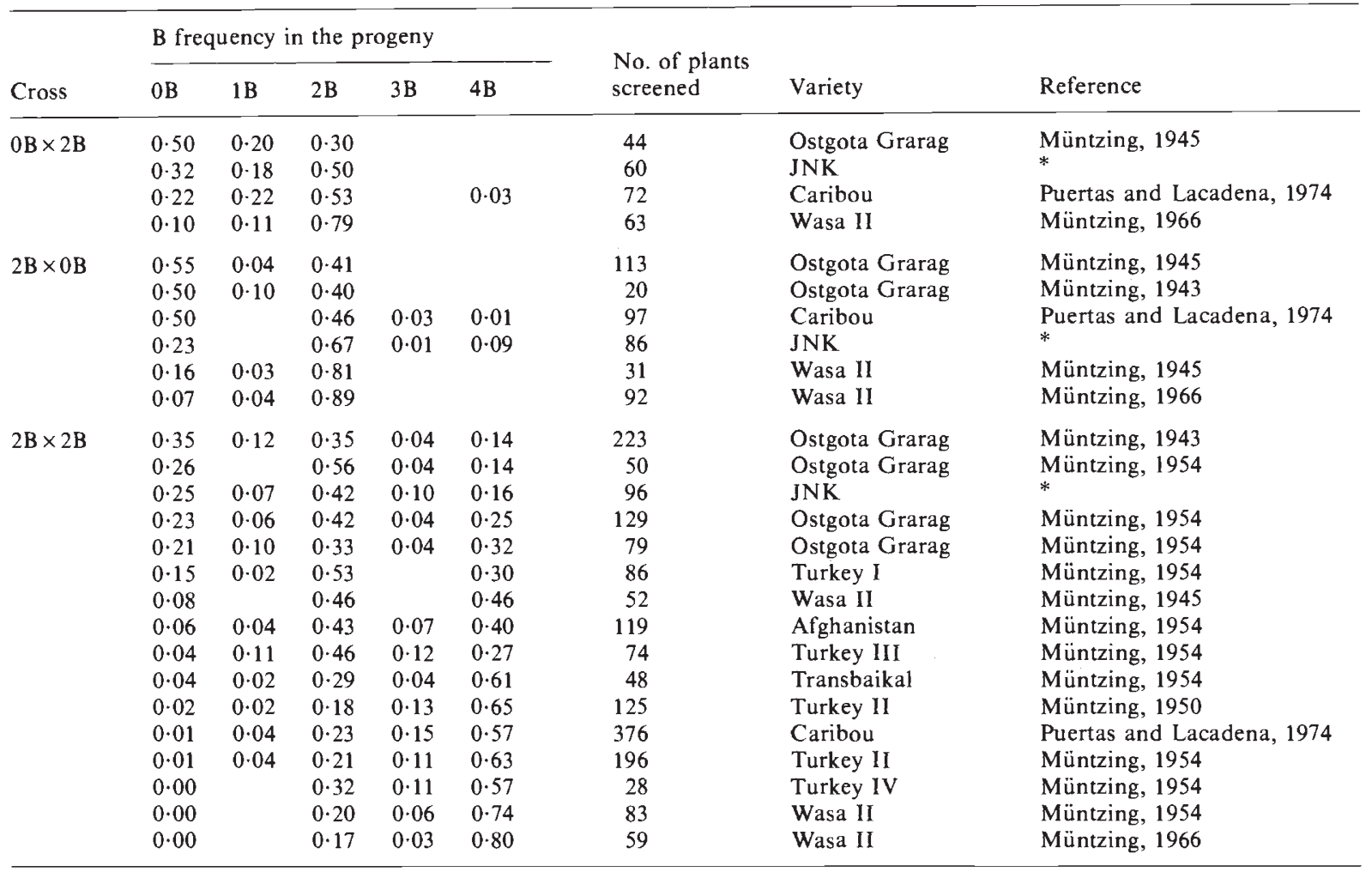

* Data of our laboratory.

or $2 \mathrm{~B}$ chromosomes from either 0 or $2 \mathrm{~B}$ maternal parents, in all possible combinations. The plants were named as follows:

$0 / 0$ : plant with $0 \mathrm{~B}$, whose maternal parent had $0 \mathrm{~B}$ 2/0: plant with $0 \mathrm{~B}$, whose maternal parent had $2 \mathrm{~B}$ $0 / 2$ : plant with $2 \mathrm{~B}$, whose maternal parent had $0 \mathrm{~B}$ 2/2: plant with $2 \mathrm{~B}$, whose maternal parent had 2B.

The number on the right is the number of Bs of the plant used in the crosses, either as male or female, and the number on the left is the number of Bs of its maternal parent.

The plants were crossed in all the 12 possible combinations involving $0 \mathrm{~B} \times 2 \mathrm{~B}, 2 \mathrm{~B} \times 0 \mathrm{~B}$ or $2 \mathrm{~B} \times$ $2 B$ crosses $(0 / 0 \times 0 / 2,0 / 2 \times 0 / 0$, etc. $)$. Four plots were made. In each plot a single type of plant was used as males (5 plants), and two $(0 / 2$ and $2 / 2$, when males had $0 B)$ or four $(0 / 0,2 / 0,0 / 2$ and $2 / 2$, when males had $2 B$ ) types of plant were used as females, with 5 plants of each type. In every case the plants used as females were emasculated, and pollen from the male plants pollinated the females at random. All the plots were isolated in such a way that open pollination within the plots was allowed, but cross-pollination among plots was prevented.

Offspring were individually collected from the females. About 25 seeds per female were screened for the B number; i.e., about 125 per cross.

As three different generations are involved in these experiments, it is worth bearing in mind that we refer to maternal parents as the plants from which we obtained the males and females used in the crosses; and offspring or progenies as the descendants obtained from the crosses.

Chromosome numbers were counted in root tips following fixation in $1: 3$ acetic alcohol and staining by the Feulgen method.

\section{RESULTS}

The progeny obtained from the $0 \mathrm{~B} \times 2 \mathrm{~B}, 2 \mathrm{~B} \times 0 \mathrm{~B}$ and $2 \mathrm{~B} \times 2 \mathrm{~B}$ groups of crosses are shown in tables 2,3 and 4 , respectively. The 16 different types of crosses were each made with five females, although in some cases the progeny of only four of them 
Table 2 Progeny obtained from $0 \mathrm{~B} \times 2 \mathrm{~B}$ crosses

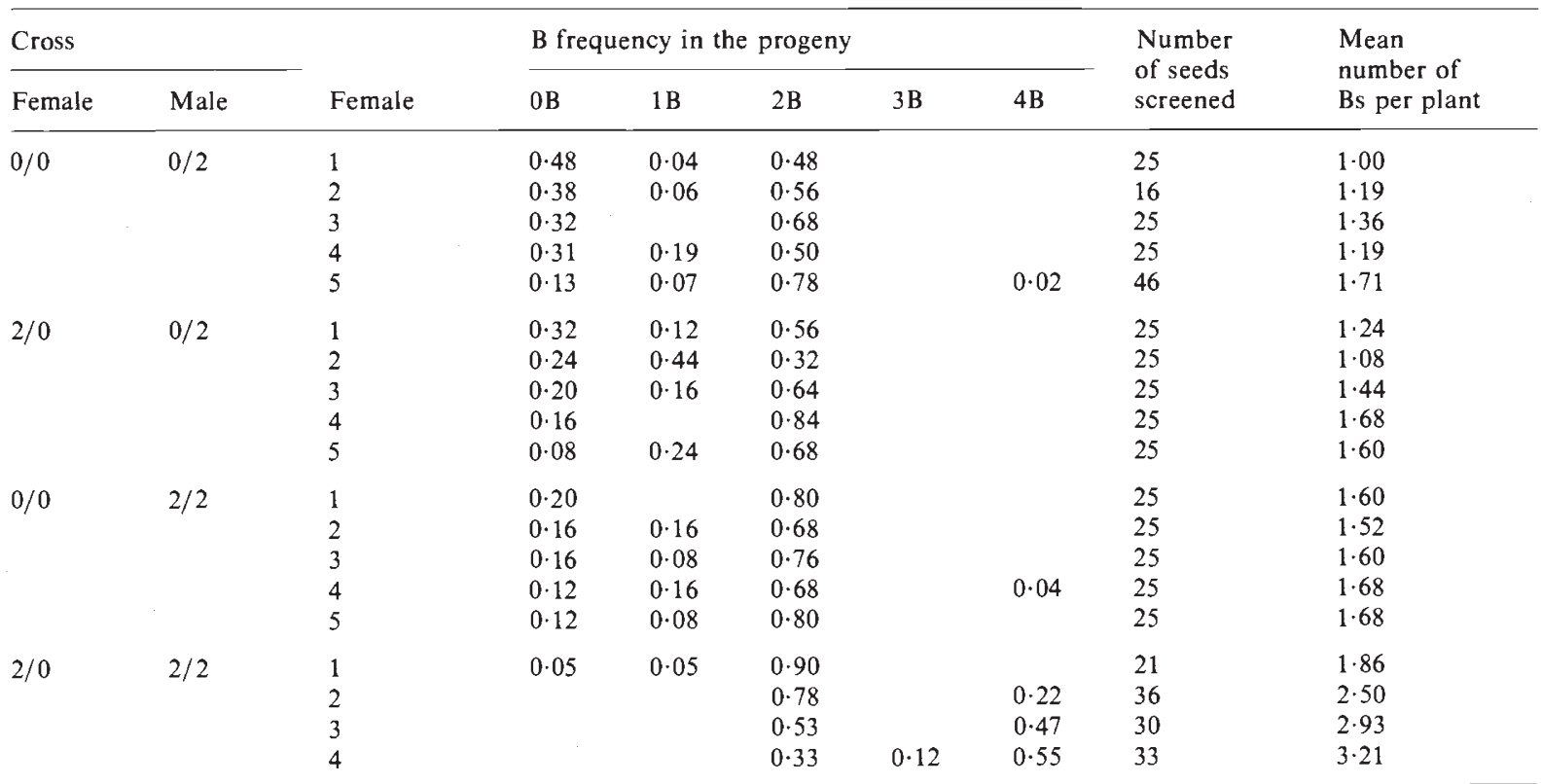

Table 3 Progeny obtained from $2 \mathrm{~B} \times 0 \mathrm{~B}$ crosses

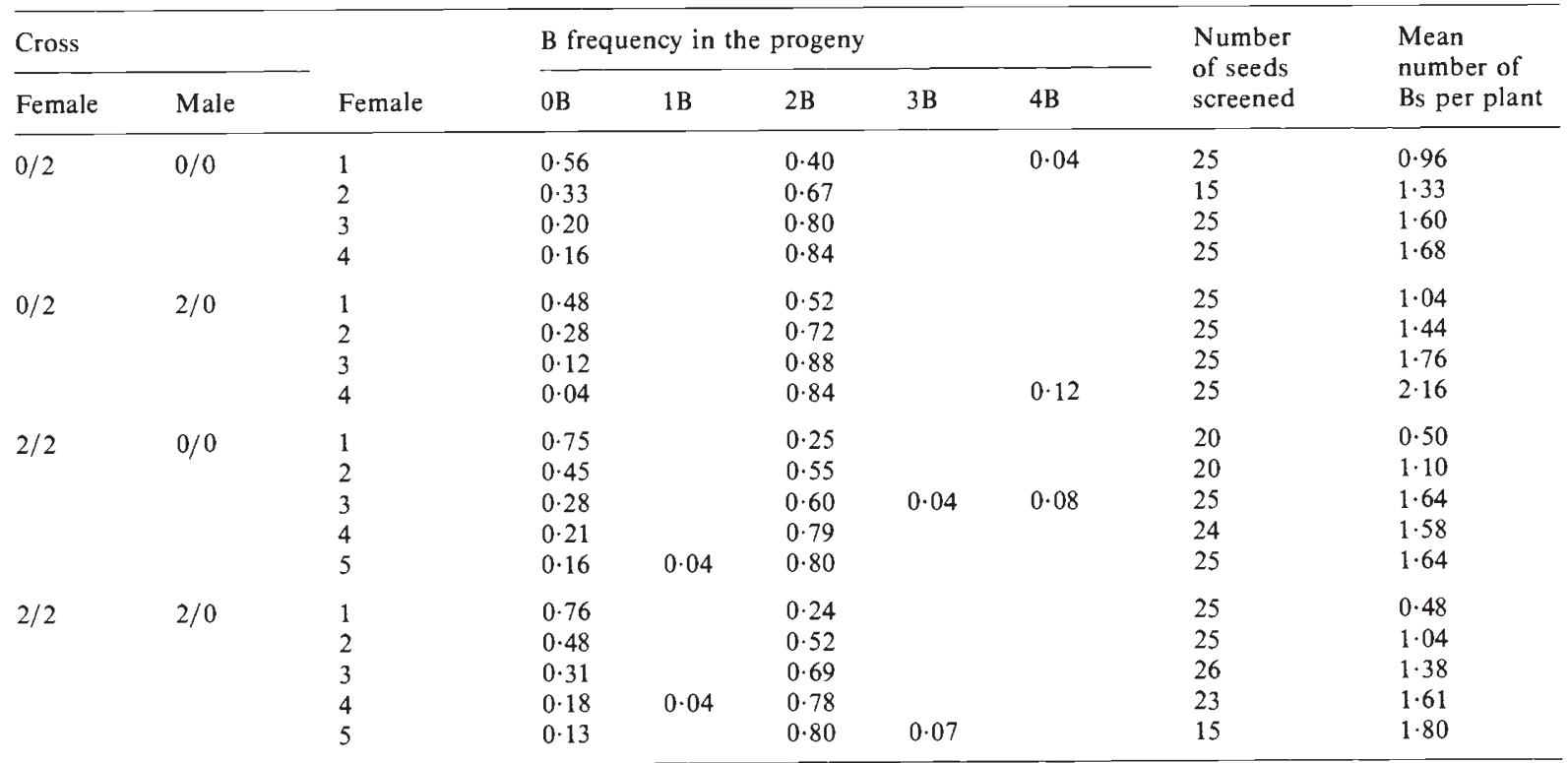

are shown, this is because counts made on less than 15 descendants of a cross were not considered. Chromosome counts were generally made in 25 seeds per female; occasionally, we made more counts in an attempt to decrease the large variance observed.

ANOVAS were made in order to compare the mean number of Bs per plant obtained in all crosses (table 5). First we compared the four types of crosses within each one of $0 \mathrm{~B} \times 2 \mathrm{~B}, 2 \mathrm{~B} \times 0 \mathrm{~B}$ or $2 \mathrm{~B} \times 2 \mathrm{~B}$ groups. Significant differences were obtained in two out of the three cases.

Since the maternal parent is the only known source of variation to account for the diifferences, we made ANOVAS to estimate whether the number of Bs of the maternal parent, both on the female 
Table 4 Progeny obtained from $2 \mathrm{~B} \times 2 \mathrm{~B}$ crosses

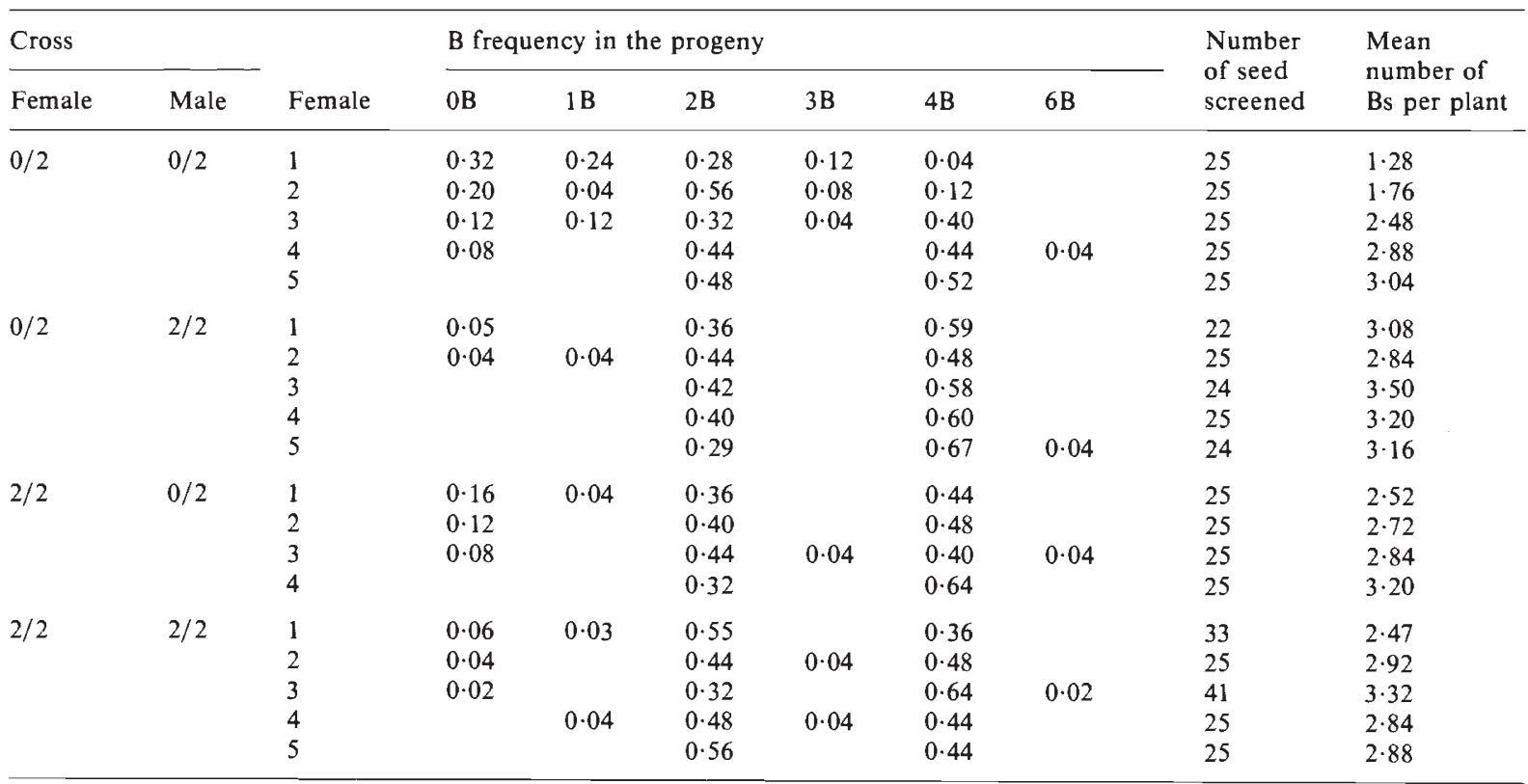

and male side, had any effect on the distribution of $\mathrm{Bs}$ in the offspring. We first compared the mean number of $\mathrm{Bs}$ obtained in $0 \mathrm{~B} \times 2 \mathrm{~B}, 2 \mathrm{~B} \times 0 \mathrm{~B}$ or $2 \mathrm{~B} \times$ $2 B$ crosses, distributed in groups with different maternal parents of the females, irrespective the maternal parent of the males, and second comparing the crosses with different maternal parents of males, irrespective the maternal parents of the females. The results were significant in several cases (table 5).

Table 6 shows the average mean of Bs per plant in all crosses. It is remarkable how large a variance there is within crosses in some cases, as shown by the mean errors; specially, the $2 \mathrm{~B} \times 0 \mathrm{~B}$ crosses

Table 5 ANOVAS comparing the offspring obtained according to their maternal parents

\begin{tabular}{|c|c|c|c|}
\hline Variable & Source of variation & Crosses compared & Level of significance \\
\hline \multirow[t]{3}{*}{ Bs per plant } & \multirow{3}{*}{$\begin{array}{l}\text { Number of Bs of the } \\
\text { maternal parent }\end{array}$} & all $0 \mathrm{~B} \times 2 \mathrm{~B}$ & $* * *$ \\
\hline & & all $2 \mathrm{~B} \times 0 \mathrm{~B}$ & $\mathrm{~ns}$ \\
\hline & & all $2 \mathrm{~B} \times 2 \mathrm{~B}$ & $*$ \\
\hline \multirow[t]{6}{*}{ Bs per plant } & \multirow[t]{3}{*}{$\begin{array}{l}\text { Number of Bs of the } \\
\text { maternal parent on } \\
\text { the female side }\end{array}$} & $\begin{array}{l}0 / 0 \times-2 \\
2 / 0 \times-2\end{array}$ & $* * *$ \\
\hline & & $\begin{array}{l}0 / 2 \times-0 \\
2 / 2 \times-0\end{array}$ & $\mathrm{~ns}$ \\
\hline & & $\begin{array}{l}0 / 2 \times-2 \\
2 / 2 \times-2\end{array}$ & $\mathrm{~ns}$ \\
\hline & \multirow{3}{*}{$\begin{array}{l}\text { Number of Bs of the } \\
\text { maternal parent on } \\
\text { the male side }\end{array}$} & $\begin{array}{l}-0 \times 0 / 2 \\
-0 \times 2 / 2\end{array}$ & $* * *$ \\
\hline & & $\begin{array}{l}-2 \times 0 / 0 \\
-2 \times 2 / 0\end{array}$ & ns \\
\hline & & $\begin{array}{l}-2 \times 0 / 2 \\
-2 \times 2 / 2\end{array}$ & $* * *$ \\
\hline
\end{tabular}

\footnotetext{
$* 0 \cdot 10>P>0 \cdot 05$.

*** significant at $0 \cdot 01$.

$\mathrm{ns}=$ nonsignificant .
} 
Table 6 Mean number of Bs per plant observed in all crosses

\begin{tabular}{|c|c|c|c|c|c|}
\hline \multicolumn{6}{|l|}{ Males } \\
\hline $2 / 2$ & $1.62 \pm 0.03$ & $2.62 \pm 0.25$ & $3 \cdot 16 \pm 0 \cdot 09$ & $2 \cdot 89 \pm 0 \cdot 12$ & \\
\hline $0 / 2$ & $1 \cdot 29 \pm 0 \cdot 11$ & $1 \cdot 41 \pm 0 \cdot 10$ & $2 \cdot 29 \pm 0 \cdot 30$ & $2 \cdot 82 \pm 0 \cdot 12$ & \\
\hline $2 / 0$ & & & $1 \cdot 60 \pm 0 \cdot 21$ & $1 \cdot 26 \pm 0 \cdot 21$ & \\
\hline \multirow[t]{2}{*}{$0 / 0$} & & & $1 \cdot 39 \pm 0 \cdot 14$ & $1 \cdot 29 \pm 0 \cdot 20$ & \\
\hline & $0 / 0$ & $2 / 0$ & $0 / 2$ & $2 / 2$ & females \\
\hline
\end{tabular}

which did not significantly differ when they were compared by an ANOVA, but the progenies obtained within each cross are highly variable (see also table 3 ).

It could be assumed that the frequency of $B$ chromosomes transmitted by $2 \mathrm{~B}$ plants as females, could be estimated from the progeny of a $2 \mathrm{~B} \times 0 \mathrm{~B}$ cross, and similarly, that male gametes could be estimated from a $0 \mathrm{~B} \times 2 \mathrm{~B}$ cross. However, our results (tables 2, 3 and 6) indicate that such assumptions could be wrong if the results of particular $2 \mathrm{~B} \times 0 \mathrm{~B}$ and $0 \mathrm{~B} \times 2 \mathrm{~B}$ crosses are considered, due to the large variation within crosses. In order to calculate the expected offspring in a $2 \mathrm{~B} \times 2 \mathrm{~B}$ cross, we considered all possible combinations among these ranges of frequencies, to obtain the distributions of Bs expected in all possible types of crosses (all possible gametes transmitted by $2 \mathrm{~B}$ females $\times$ male gametes transmitted in a $0 / 0 \times 0 / 2$ cross; all possible gametes transmitted by $2 \mathrm{~B}$ females $\times$ male gametes transmitted in a $0 / 0 \times 2 / 2$ cross, and so on). These distributions were considered in various combinations and the values were grouped in two intervals (1 to $3 \mathrm{Bs}$ and $3 \mathrm{Bs}$ or more) and compared with the observed distributions (table 7). Only two intervals were made since we have only 19 observed results in $2 \mathrm{~B} \times 2 \mathrm{~B}$ crosses and the $\chi^{2}$ value could not be calculated if more classes were considered. Even with only two classes, some $\chi^{2}$ values could not be calculated, although in those cases similarities of dissimilarities between the observed and expected distributions are obvious.

\section{DISCUSSION}

Rye is one of the species in which many results of controlled crosses to study the transmission of B chromosomes have been reported. However, the genetic system of B chromosomes is still poorly understood, due to its uniqueness and wide departure from Mendelian rules.

Table 1 (modified from Matthews, 1981) shows all the results, reported to date, of crosses involving $\mathrm{OB}$ and $2 \mathrm{~B}$ plants. It is arranged with the progenies ordered from higher to lower frequency of $0 \mathrm{~B}$ plants, and shows several remarkable features of the data.

Table 7 Distribution of the observed and expected frequencies of $\mathrm{B}$ chromosomes in $2 \mathrm{~B} \times 2 \mathrm{~B}$ crosses

\begin{tabular}{|c|c|c|c|c|}
\hline $\begin{array}{l}\text { Crosses } \\
\text { compared }\end{array}$ & Intervals & Observed & Expected & $\chi^{2}$ \\
\hline Obs.: $2 \mathrm{~B} \times 2 \mathrm{~B}$ & 1 to $3 \mathrm{Bs}$ & 12 & $9 \cdot 55$ & \multirow[t]{2}{*}{ ns } \\
\hline Exp.: $2 \mathrm{~B} \times 2 \mathrm{~B}$ & 3 or more & 7 & $9 \cdot 45$ & \\
\hline Obs.: $2 \mathrm{~B} \times 2 \mathrm{~B}$ & 1 to $3 \mathrm{Bs}$ & 12 & $11 \cdot 40$ & \multirow[t]{2}{*}{ ns } \\
\hline Exp.: $0 / 0 \times-2$ & 3 or more & 7 & $7 \cdot 60$ & \\
\hline Obs.: $2 \mathrm{~B} \times 2 \mathrm{~B}$ & 1 to $3 \mathrm{Bs}$ & 12 & $7 \cdot 50$ & \multirow[t]{2}{*}{$*$} \\
\hline Exp.: $2 / 0 \times-2$ & 3 or more & 7 & $11 \cdot 50$ & \\
\hline Obs.: $2 \mathrm{~B} \times 0 / 2$ & 1 to $3 \mathrm{Bs}$ & 7 & $7 \cdot 10$ & \multirow[t]{2}{*}{$\dagger$} \\
\hline Exp.: $0 / 0 \times 0 / 2$ & 3 or more & 2 & $1 \cdot 90$ & \\
\hline Obs.: $2 \mathrm{~B} \times 0 / 2$ & 1 to $3 \mathrm{Bs}$ & 7 & $5 \cdot 60$ & \multirow[t]{2}{*}{ ns } \\
\hline Exp.: $2 / 0 \times 0 / 2$ & 3 or more & 2 & $4 \cdot 40$ & \\
\hline Obs.: $2 \mathrm{~B} \times 0 / 2$ & 1 to $3 \mathrm{Bs}$ & 7 & $6 \cdot 35$ & \multirow[t]{2}{*}{$\dagger$} \\
\hline Exp.: $-0 \times 0 / 2$ & 3 or more & 2 & $2 \cdot 65$ & \\
\hline Obs.: $2 \mathrm{~B} \times 0 / 2$ & 1 to $3 \mathrm{Bs}$ & 7 & $2 \cdot 5$ & \multirow[t]{2}{*}{$\ddagger$} \\
\hline Exp.: $-0 \times 2 / 2$ & 3 or more & 2 & $6 \cdot 5$ & \\
\hline Obs.: $2 \mathrm{~B} \times 2 / 2$ & 1 to $3 \mathrm{Bs}$ & 5 & $4 \cdot 11$ & \multirow[t]{2}{*}{ ns } \\
\hline Exp.: $0 / 0 \times 2 / 2$ & 3 or more & 5 & $5 \cdot 89$ & \\
\hline Obs.: $2 \mathrm{~B} \times 2 / 2$ & 1 to $3 \mathrm{Bs}$ & 5 & $1 \cdot 11$ & \multirow[t]{2}{*}{$\ddagger$} \\
\hline Exp.: $2 / 0 \times 2 / 2$ & 3 or more & 5 & 8.89 & \\
\hline Obs.: $2 \mathrm{~B} \times 2 / 2$ & 1 to $3 \mathrm{Bs}$ & 5 & $2 \cdot 77$ & \multirow[t]{2}{*}{$\ddagger$} \\
\hline Exp.: $-0 \times 2 / 2$ & 3 or more & 5 & $7 \cdot 22$ & \\
\hline Obs.: $2 \mathrm{~B} \times 2 / 2$ & 1 to $3 \mathrm{Bs}$ & 5 & $7 \cdot 05$ & \multirow[t]{2}{*}{$\ddagger$} \\
\hline Exp.: $-0 \times 0 / 2$ & 3 or more & 5 & $2 \cdot 95$ & \\
\hline
\end{tabular}

ns = nonsignificant.

* significant at 0.05 .

$\dagger \chi^{2}$ cannot be calculated, but observed and expected distributions are very similar.

$\ddagger \chi^{2}$ cannot be calculated, but observed and expected distributions are very different. 
(i) Very large differences in B chromosome frequency are observed within the offspring obtained from $0 \mathrm{~B} \times 2 \mathrm{~B}, 2 \mathrm{~B} \times 0 \mathrm{~B}$ and $2 \mathrm{~B} \times 2 \mathrm{~B}$ crosses. It can be concluded that $2 \mathrm{~B}$ plants transmit B chromosomes with very variable frequencies.

(ii) It seems that there are rye varieties which tend to form many $0 \mathrm{~B}$ plants (i.e., Ostgota Grarag), while others tend to transmit many Bs (Wasa II). However, this relation with the variety is not complete; for example, the results with Turkey and Wasa II are rather variable in $2 \mathrm{~B} \times 2 \mathrm{~B}$ crosses.

(iii) Theoretically, the frequency of the gametes carrying B chromosomes transmitted by a $2 \mathrm{~B}$ plant either as male or female, can be estimated from the progenies obtained in $0 \mathrm{~B} \times 2 \mathrm{~B}$ and $2 \mathrm{~B} \times 0 \mathrm{~B}$ crosses respectively; and in this way, the expected progeny of a $2 \mathrm{~B} \times 2 \mathrm{~B}$ cross can be calculated. Let $\mathrm{m}_{0}, \mathrm{~m}_{1}$ and $\mathrm{m}_{2}$ be the gametes with 0,1 or $2 \mathrm{Bs}$ transmitted by a $2 \mathrm{~B}$ plant in a $0 \mathrm{~B} \times 2 \mathrm{~B}$ cross, and $\mathrm{f}_{0}, \mathrm{f}_{1}$ and $\mathrm{f}_{2}$ the gametes with 0,1 or $2 \mathrm{Bs}$ transmitted by a $2 \mathrm{~B}$ plant in a $2 \mathrm{~B} \times 0 \mathrm{~B}$ cross. The expected distribution of $B s$ in a $2 B \times 2 B$ cross is $m_{0} \times f_{0}$ of $0 \mathrm{~B},\left(\mathrm{~m}_{0} \times \mathrm{f}_{1}+\mathrm{m}_{1} \times \mathrm{f}_{0}\right)$ of $1 \mathrm{~B}$, and so on. As a matter of fact, the progeny observed in $2 \mathrm{~B} \times$ $2 \mathrm{~B}$ crosses significantly differ from expected in all cases. This can be verified in the varieties Ostgota Grarag, JNK, Caribou and Wasa II which appear in the three groups of table 1. For example, in Caribou 53 per cent of gametes with $2 \mathrm{~B}$ were transmitted in the $0 \mathrm{~B} \times$ $2 \mathrm{~B}$ cross, and 46 per cent in the $2 \mathrm{~B} \times 0 \mathrm{~B}$. So that 24 per cent of $4 \mathrm{~B}$ plants are expected in the $2 \mathrm{~B} \times 2 \mathrm{~B}$ cross, while more than double this frequency were observed. The deviation between observed and expected distributions in $2 \mathrm{~B} \times 2 \mathrm{~B}$ progenies does not follow any apparent pattern. For example, in Ostgota Grarag and Caribou about double the number of $4 \mathrm{~B}$ plants were observed than expected, in JNK it was just the opposite, while in Wasa II there was no difference for this class.

In the crosses made in this work we observe a remarkably large variation of $\mathrm{B}$ chromosome frequency obtained in the progenies (tables 2, 3, and 4). For example, the frequency of $0 \mathrm{~B}$ plants varies from 0 to 48 per cent in $0 \mathrm{~B} \times 2 \mathrm{~B}$ crosses, from 4 to 76 per cent in $2 \mathrm{~B} \times 0 \mathrm{~B}$, and from 0 to 32 per cent in $2 \mathrm{~B} \times 2 \mathrm{~B}$. It should also be noted that the variation observed in the crosses made in this work, with a single variety, is of the same magnitude to that observed in table 1 for many different varieties. This variation cannot be explained by any of the features of rye $\mathrm{B}$ chromosomes known to date.

We shall demonstrate that one of the causes of this variation in the transmission rate of $\mathrm{B}$ chromosomes is whether or not the maternal parent of the plants involved in the crosses carried B chromosomes. In addition, we shall see that another still unknown cause must be also involved.

\section{$O B \times 2 B$ crosses (table 2)}

It is our repeated experience that the frequency of pollen grain types expected to participate in pollination, based on direct observation of chromosome numbers at pollen mitosis, differs markedly from the progeny types observed in a $0 \mathrm{~B} \times 2 \mathrm{~B}$ cross (Puertas et al., 1986, 1988). In all the rye varieties in which we have studied pollen grain mitosis (Puertas et al., 1979; Romera et al., 1989), a remarkable similarity was observed, irrespective of the variety: a $2 \mathrm{~B}$ plant forms about 5 per cent of pollen grains with $0,1,3$ or $4 \mathrm{Bs}$ and the remaining $80-85$ per cent have $2 \mathrm{Bs}$. These frequencies of pollen types formed differ greatly from the frequncies obtained in the offspring of $0 \mathrm{~B} \times 2 \mathrm{~B}$ crosses.

It is remarkable that in the crosses $0 / 0 \times 0 / 2$, $2 / 0 \times 0 / 2$ and $0 / 0 \times 2 / 2$ the frequency of descendants with $0 \mathrm{~B}$ was high, while in the cross $2 / 0 \times 2 / 2$ the frequency of $4 \mathrm{~B}$ plants was high with almost no $0 \mathrm{~B}$ plants. All these results are far from expected, according to the frequencies of pollen formed, and indicate that the difference, in all probability, is due to differential fertilisation and not to differential viability of zygotes carrying different number of $\mathrm{B}$ chromosomes.

In spite of the high frequency of $0 \mathrm{~B}$ plants in some cases, the mean number of Bs per plant transmitted in all crosses is higher than 1 (only in one case is equal to 1), indicating a preferential transmission of B chromosomes to the offspring.

It is evident that the four groups of crosses shown in table 2 are different, as demonstrated by the corresponding ANOVA (table 5). It is also evident that the B status of the maternal parent, on both the male and female side, has an essential role in accounting for the differences: $2 / 2$ males produce more $\mathrm{Bs}$ in the offspring than $0 / 2$ males on any $0 \mathrm{~B}$ female, and more $\mathrm{Bs}$ were produced in $2 / 0$ females than in $0 / 0$ ones (table 6 ). The joint effect of $0 / 2$ males and $0 / 0$ females produces a remarkable increase of $0 \mathrm{~B}$ descendants, while the joint effect of $2 / 2$ males and $2 / 0$ females produces a remarkable increase of $4 \mathrm{~B}$ descendants. It should be noted that only about 3 per cent $0 \mathrm{~B}$ and 2 per cent $4 \mathrm{~B}$ pollen grains are produced, while about 
50 per cent were transmitted in some cases. As was mentioned above, this increase of $0 \mathrm{~B}$ and $4 \mathrm{~B}$ descendants has been observed in previous works, although these results are so unexpected, particularly the increase of 4B plants, that we consider that these crosses should be further investigated.

In previous works (Puertas et al., 1986, 1988) we have hypothesised the existence of pollen-style interactions to explain the competition of different types of pollen grains on $0 \mathrm{~B}$ stigmas. The results of this work show that at least one of the causes of such differential fertilisation is the B status of the maternal parent of plants involved in $0 \mathrm{~B} \times 2 \mathrm{~B}$ crosses: (i) when pollen grains are formed in $2 \mathrm{~B}$ plants whose maternal parent had $2 \mathrm{~B}$, they transmit Bs with high efficiency; (ii) when stigmas belong to $0 \mathrm{~B}$ plants whose maternal parent had $2 \mathrm{~B}$, they accept Bs with high efficiency; (iii) when these two effects occur together, the number of Bs transmitted to offspring is very high; (iv) the opposite is also true, when pollen is formed in $2 \mathrm{~B}$ plants whose maternal parent had $\mathrm{OB}$ it transmits the Bs with low efficiency, when the styles belong to $0 \mathrm{~B}$ plants whose maternal parent had $0 \mathrm{Bs}$ they better accept $0 \mathrm{~B}$ pollen, and therefore, the minimum frequency of $\mathrm{Bs}$ is obtained in $0 / 0 \times 0 / 2$ crosses.

\section{$2 B \times O B$ crosses (table 3)}

In this case the transmission data cannot be compared with the cytological data, since female gametogenesis is difficult to observe, specially in a quantitative analysis. However, according to the results of crosses, we can deduce that nondisjunction of B chromosomes occurred in all cases since $1 \mathrm{~B}$ descendants were almost never observed. This small number of 1B descendants has also been observed in other rye varieties (table 1).

It is also interesting to note that in several cases the mean number of Bs transmitted was less than $1 \mathrm{~B}$ per plant, which means that the transmission of Bs is not always preferential on the female side, indicating a less efficient mechanism of transmission than on the male side; however, the average mean of Bs transmitted was higher than 1 in all crosses (table 6).

A very large variation within crosses, with double or triple differences, was observed. The ANOVA (table 5) indicate that there are not significant differences among the four types of $2 \mathrm{~B} \times 0 \mathrm{~B}$ crosses. The slight interaction between $2 \mathrm{~B}$ females and $0 \mathrm{~B}$ males was also noted in previous works (Puertas et al., 1988), in which we did not detect competition between $\mathrm{OB}$ and $2 \mathrm{~B}$ pollen on $2 \mathrm{~B}$ females. However, this does not mean than the maternal parent on the female side does not affect the transmission of $\mathrm{Bs}$, as it does on the male side. When crosses are compared according to the number of Bs of the maternal parent on the female side (table 5) there are significant differences between $0 / 0$ and $2 / 0$ females.

We think that the variation within each type of $2 \mathrm{~B} \times 0 \mathrm{~B}$ cross is produced by another cause, which is still unknown. Genotypes affecting the rate of transmission of B chromosomes in females could account for this variation, but this possibility has to be further investigated. Such hypothetical genotypes would have a stronger effect than that of the maternal parent of females, producing this large variance and obscuring its effect. It is possible that on the female side two effects occur together, one gametophytic and depending on the genotype of the female, and the other sporophytic and depending on the maternal parent. In the two animal species Myrmeleotettix maculatus and Pseudococcus affinis, genotypes affecting the transmission rate of $\mathrm{B}$ chromosomes have been reported (Shaw, and Hewitt, 1985; Shaw et al., 1985; Nur and Brett, 1987, 1988).

\section{$2 B \times 2 B$ crosses (table 4)}

The intra-cross variation, together with the interactions that we have just discussed, make it impossible to estimate the expected distribution of progenies of $2 \mathrm{~B} \times 2 \mathrm{~B}$ crosses, according to the observations of one or a few $2 \mathrm{~B} \times 0 \mathrm{~B}$ and $0 \mathrm{~B} \times 2 \mathrm{~B}$ particular crosses. This is, in all probability the reason why the $2 \mathrm{~B} \times 2 \mathrm{~B}$ crosses shown in table 1 do not fit with expectations in any case or variety. A 2 B plant in a $0 B \times 2 B$ cross transmits different male gametes according to its maternal parent and the maternal parent of the female that it fertilises (table 2), and in $2 \mathrm{~B} \times 0 \mathrm{~B}$ crosses it transmits female gametes with a mean number of Bs ranging from 0.48 to $2 \cdot 16$ (table 3 ). Therefore, in order to calculate the expected distributions, all of this variation has to be taken into account. Table 7 shows the comparisons made between the observed results and the expected distributions calculated on the basis of the explanation given above.

The distribution of the mean number of Bs per plant observed in $2 \mathrm{~B} \times 2 \mathrm{~B}$ crosses does not differ significantly from either the total expected, or from that expected considering only the male gametes transmitted by a $2 \mathrm{~B}$ male on a $0 / 0$ female, while it does differ significantly when we consider the pollen transmitted by a $2 \mathrm{~B}$ male on a $2 / 0$ female. This shows again the interaction of $2 / 0$ females 
with $2 \mathrm{~B}$ pollen and the effect of the male maternal parent on the transmission of $\mathrm{B}$ chromosomes.

In addition to the total observed in $2 \mathrm{~B} \times 2 \mathrm{~B}$ crosses, we have considered the partial results of either $2 \mathrm{~B} \times 0 / 2$ or $2 \mathrm{~B} \times 2 / 2$. In many of these cases $\chi^{2}$ value could not be calculated, but similarities or dissimilarities between the observed and expected distributions are so obvious that we can obtain some conclusions.

The observed distribution of $2 \mathrm{~B} \times 0 / 2$ crosses fits well with any expectation in which a $0 / 2$ male is considered, irrespective of the female. However, the distribution is very different when a $2 / 2$ male is considered. This again indicates the strong interaction produced due to the $2 \mathrm{~B}$ maternal parent.

The observed distribution of $2 \mathrm{~B} \times 2 / 2$ crosses only fits with expectations calculated with $0 / 0 \times$ $2 / 2$ crosses, indicating again the strong interaction of $2 / 2$ pollen with any female having a $2 \mathrm{~B}$ maternal parent.

We can finally conclude that $2 \mathrm{~B}$ plants produce an imprinting which affects their descendants in such a way that first, all their descendants can be recognised whether they carry Bs or not and second, they increase the frequency of transmission of $\mathrm{B}$ chromosomes through $2 / 2$ males on $2 / 0$ females, while a $0 \mathrm{~B}$ maternal parent makes for a decrease in frequency through $0 / 2$ males on $0 / 0$ females. This interaction seems to be both sporophytic and gametophytic since on one hand pollen-style recognitions occur according to the maternal parent, and on the other hand particular types of pollen ( $0 \mathrm{~B}$ or $4 \mathrm{~B})$ are greatly increased in frequency over the level at which they are produced in some cases.

The results obtained in this work are unexpected in several respects, and they show how far the behaviour of $\mathrm{B}$ chromosomes is from Mendelian rules. They also show that the maintenance of $B$ chromosomes in populations depends on very complicated interactions that should be further investigated. We believe that these interactions have an important effect at the population level on the maintenance of the polymorphism for B chromosomes.

Acknowledgements This work was supported by the grants 609.2-803.002 from the Complutense University, and PB88-1022 from the CICYT of Spain

\section{REFERENCES}

KISHIKAWA, H. 1965. Cytogenetic studies of B chromosomes in rye, Secale cereale in Japan. Agr. Bul. Saga Univ., 21, $1-81$.

HÅKANSON, A. 1948. Behaviour of accessory chromosomes in the embryo sac. Hereditas, 34, 35-39.

MatThews, R. B. 1981. Studies on B Chromosomes with Particular Reference to Plant Disease. Ph.D. Thesis, University of Wales.

MÜNTZING, A. 1943. Genetical effects of duplicated fragment chromosomes in rye. Hereditas, 29, 91-112.

MÜNTZING, A. 1945. Cytological studies of extra fragment chromosomes in rye II. Transmission and multiplication of standard fragments and iso-fragments. Hereditas, 31 , 457-477.

MÜNTZING, A. 1946. Cytological studies of extra fragment chromosomes in rye III. The mechanism of non-disjunction at the pollen mitosis. Hereditas, 32, 507-509.

MÜNTZING, A. 1950. Accessory chromosomes in rye populations from Turkey and Afghanistan. Hereditas, 36, 507-509.

MÜNTZING, A. 1954. Cytogenetics of accessory chromosomes (B chromosomes). Caryologia, Suppl., 6, 282-301.

MÜNTZING, A. 1966. Some recent data on accessory chromosomes in Secale and Poa. Chromosomes Today, 1, 7-14.

NUR, U. AND BRETT, B. L. H. 1987. Control of meiotic drive of B chromosomes in the mealybug Pseudococcus affinis (obscurus). Genetics, 115, 499-510.

NUR, U. AND BRETT, B. L. H. 1988. Genotypes affecting the condensation and transmission of heterochromatic $B$ chromosomes in the mealybug Pseudococcus affinis. Chromosoma (Berl), 96, 205-212.

PUERTAS, M. J., BAEZA, F. AND DE LA PEÑA, A. 1986. The transmission of B chromosomes in populations of Secale cereale and Secale vavilovii 1 . Offspring obtained from $0 \mathrm{~B}$ and 2B plants. Heredity, 57, 389-394.

PUERTAS, M. J., DIEZ, M. AND CARMONA R. 1979. Rye B chromosome behaviour at first and second pollen mitosis and its relationship with anther maturity. Theor. Appl. Genet., 54, 65-68.

PUERTAS, M. J. AND LACADENA, J. R. 1974. The transmission of rye B chromosomes in natural pollination. Theor. Appl. Genet., 45, 195-204.

PUERTAS, M. J., VEGA, J. M., ROMERA, F. AND DIEZ, M. 1988. Frequency dependent fertilisation involving rye B chromosomes. Heredity, 61, 143-147.

ROMERA, F., VEGA, J. M. AND PUERTAS, M. J. 1989. B chromosome polymorphism in Korean rye populations. Heredity, 62, 117-121.

SHAW, M. W. AND HEWITT, G. M. 1985. The genetic control of meiotic drive acting on the B chromosome of Myrmeleotettix maculatus (Orthoptera: Acrididae). Heredity, 54, 187 194.

SHAW, M. W., HEWITT, G. M. AND ANDERSON, D. A. 1985 Polymorphism in the rates of meiotic drive acting on the B chromosome of Myrmeleotettix maculatus. Heredity, 55, 61-68. 